\title{
DEIONIZAÇÃO CAPACITIVA PARA DESSALINIZAÇÃO DE ÁGUA
}

\author{
L. A. M. RUOTOLO ${ }^{1}$, M. I. TEJEDOR-TEJEDOR ${ }^{2}$ e M. A. ANDERSON ${ }^{2,3}$ \\ ${ }^{1}$ Universidade Federal de São Carlos, Departamento de Engenharia Química \\ ${ }^{2}$ University of Wisconsin-Madison, Environmental Science and Technology Program \\ ${ }^{3}$ Instituto Madrileño de Estudios Avanzados, Unidad de Procesos Electroquímicos \\ E-mail para contato: pluis@ufscar.br
}

\begin{abstract}
RESUMO - Neste trabalho estudou-se a dessalinização de água usando tecnologia de deionização capacitiva (DIC). DIC é um processo eletroquímico que opera adsorvendo íons na dupla camada elétrica formada na interface eletrodo-solução através da aplicação de uma diferença de potencial entre dois eletrodos. Estudou-se o efeito do modo operacional (galvanostático, potenciostático e pulsos de potencial) sobre a remoção de $\mathrm{NaCl}$ de soluções aquosas. Os eletrodos de carbono utilizados foram fornecidos pela Hollingsworth \& Vose e funcionavam como cátodo e ânodo em uma célula de DIC que operava em batelada com recirculação. Após o ciclo de deionização os eletrodos eram regenerados colocando-se o sistema em curto-circuito. A concentração de $\mathrm{NaCl}$ foi determinada a partir de medidas on line da condutividade da solução. $\mathrm{O}$ processo de eletrossorção foi avaliado em termos da cinética de dessalinização e consumo energético. Os resultados mostraram que o uso de potencial pulsante não promovia uma melhoria no processo de dessalinização quando comparado com a aplicação de um potencial constante. As melhores taxas de remoção, eficiência coulômbica e consumo energético foram obtidos utilizando-se o modo galvanostático.
\end{abstract}

\section{INTRODUÇÃO}

Processos que visam a deionização de águas são extremamente desejáveis atualmente para solucionar problemas como o abastecimento de água potável, tratamento de água para uso residencial e na indústria e para tratamento de efluentes industriais. Neste sentido, a deionização capacitiva surgiu como uma alternativa tecnológica bastante atrativa, pois utiliza os conceitos de capacitância da dupla camada elétrica para a eletrossorção de cátions e ânions. Além disso, durante o ciclo de regeneração, há ainda a possibilidade de recuperação de parte da energia armazenada durante o ciclo de adsorção. Todas estas características tornam o processo de deionização capacitiva bastante competitivo em termos energéticos e de custos de capital com tecnologias já estabelecidas e utilizadas industrialmente, como a osmose reversa e a destilação. No entanto, alguns desafios devem ser superados para que o processo DIC possa ser efetivamente implantado, sendo um deles a cinética e a capacidade de remoção do processo em função das variáveis operacionais. 


\subsection{Dessalinização de águas salobras}

O aumento do crescimento populacional nos últimos séculos, aliado ao crescimento tecnológico e científico tem sido responsável pelo aumento das atividades agrícolas e industriais e, consequentemente, pelo consumo cada vez maior dos recursos naturais e energéticos. Em todo o mundo as indústrias consomem cerca de $20 \%$ da água captada, sendo o restante $69 \%$ para agricultura e $8 \%$ para o consumo doméstico. Essa larga utilização na indústria revela a importância desse recurso natural como fator de produção de bens.

Por outro lado, um dos maiores desafios do mundo moderno envolve o tratamento, manutenção e conservação dos recursos aquáticos. Energia e meio ambiente têm recentemente recebido muita atenção, sendo que a água tem sido declarada como "petróleo do século" pela Fortune Magazine em 2000 (Leonard et al., 2009). Várias aplicações na área de tratamento de água podem ser citadas, entre elas destaca-se a dessalinização de águas salobras.

Embora o Brasil possua o maior reservatório de água doce no planeta, com $8 \%$ das reservas mundiais e $18 \%$ da água superficial, esta água não está igualmente distribuída no território brasileiro, sendo que $80 \%$ deste recurso está concentrado na região amazônica, onde vive apenas $8 \%$ da população brasileira. Por outro lado, a região nordeste concentra $27 \%$ da população e tem acesso a somente 3,3\% da água disponível. Portanto, o fornecimento de água potável para a população do nordeste brasileiro é atualmente um dos problemas mais desafiadores para ajudar esta região a se tornar economicamente e socialmente desenvolvida.

O nordeste brasileiro é caracterizado pelo clima semiárido em que altas temperaturas, elevados índices de evaporação e baixos índices pluviométricos tornam a água muito escassa. De acordo com o Instituto Nacional Semiárido, o semiárido brasileiro cobre uma área de aproximadamente $980.133 \mathrm{~km}^{2}$, o que corresponde a $63 \%$ e $12 \%$ do território nordestino e brasileiro, respectivamente. Aproximadamente 22,5 milhões de pessoas $(11,8 \%$ da população brasileira) vive no semiárido, o qual demonstra o menor IDH (Índice de Desenvolvimento Humano) brasileiro. Apesar da indisponibilidade de água superficial na região semiárida, de acordo com a Associação Brasileira de Água Subterrânea - ABAS, pelo menos 19,5 bilhões de $\mathrm{m}^{3}$ de água por ano a água poderiam ser extraídos do subsolo sem qualquer risco de exaustão (Soares et al.,2006). Entretanto, o uso desta água é limitado pela sua alta concentração de sais. Uma grande parte do território semiárido $\left(788.000 \mathrm{~m}^{2}\right)$ é composta por rochas cristalinas cujo contato prolongado com a água tornou-a salobra. Além de a água ser indispensável para vida, ela também é necessária para o desenvolvimento econômico e sua escassez está associada à miséria no semiárido. Portanto, a dessalinização da água salobra do subsolo além de prover água potável para ao consumo humano, também tem o papel de alavancar o desenvolvimento econômico da região.

Neste contexto, o governo brasileiro vem encorajando o uso de métodos de dessalinização para a produção de água potável. Em 2004, de acordo com a Associação dos Geógrafos Brasileiros - AGB, existiam mais de 3000 sistemas de dessalinização instalados na região semiárida brasileira. Infelizmente, a maior parte deles não está funcionando adequadamente devido à falta de manutenção ou devido ao mau uso. $\mathrm{O}$ método predominante utilizado para a dessalinização no nordeste brasileiro é a osmose reversa (OR), a qual possui desvantagens como a calcificação e incrustação, alto consumo de energia devido ao uso de bombas de alta pressão bem como a dificuldade de operação e manutenção. Outros processos 
comumente utilizados para dessalinização são a destilação flash de múltiplos efeitos (DFM) e a eletrodiálise (EDI), os quais se caracterizam pelo elevado consumo de energia devido à necessidade de elevadas voltagens (EDI) e de grandes quantidades de calor (DFM). No caso da OR e da EDI, além do elevado consumo de energia elétrica, há também a necessidade de utilização de membranas que elevam o custo de capital e estão sujeitas a incrustação (fouling).

Diante deste cenário, novas tecnologias vêm sendo estudadas e desenvolvidas para diminuir o consumo energético e garantir um processo de fácil manutenção e operação. Assim surgiu a "deionização capacitiva" (DIC), mais conhecida pela sua sigla em inglês CDI (capacitive deionization). O processo DIC é bastante parecido com seu parente mais próxima, a EDI, pois os dois baseiam-se na aplicação de uma diferença de potencial elétrico entre dois eletrodos. Porém, enquanto na EDI ocorrem processos faradáicos no cátodo e no ânodo, induzindo então os íons de carga contrária para compartimentos separados por membranas catiônicas e aniônicas, no processo DIC a voltagem aplicada é menor, ou seja, o custo energético diminui, e a necessidade de membranas é eliminada, ou seja, diminuindo drasticamente o custo do equipamento.

\subsection{Deionização capacitiva}

O processo de deionização capacitiva, muitas vezes chamado de eletrossorção, opera aplicando-se uma diferença de voltagem, induzindo assim as espécies eletricamente carregadas (íons), para os eletrodos com cargas opostas, porém sem a utilização de membranas e não envolvendo, portanto, pressões elevadas (Figura 1(a)). Assim sendo a DIC tem a possibilidade de competir diretamente com a OR, a EDI e a DFM como um método para produção e de água deionizada a um custo reduzido, com condições operacionais simples.

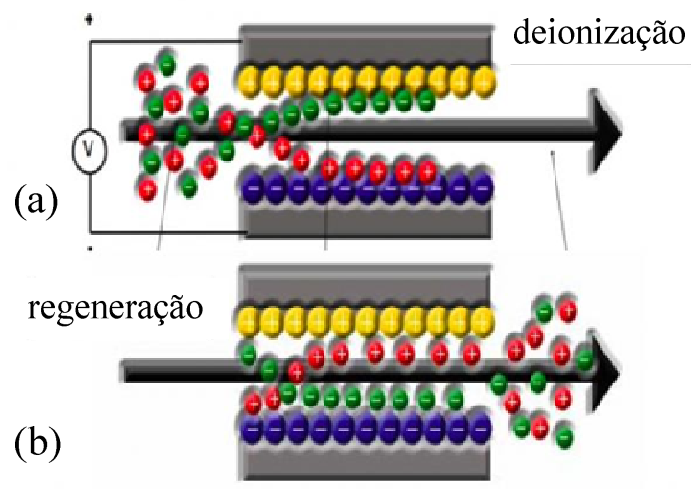

Figura 1 - Representação esquemática do processo DC em que cátions são seqüiestrados no eletrodo negativo e ânions são seqüestrados no eletrodo positivo durante o processo de eletrossorção. Durante a regeneração, cátions e ânions são dessorvidos e liberados na solução.

A DIC é um processo eletroquímico que opera adsorvendo íons na dupla camada elétrica formada na interface eletrodo/eletrólito através da aplicação de uma diferença de potencial. Após a deionização os eletrodos podem ser regenerados para outro ciclo de adsorção apenas deixando o sistema em condições de circuito aberto ou então revertendo o potencial aplicado (Figura 1(b)). A regeneração sob condição de circuito aberto pode ser muito lenta, enquanto na aplicação de um potencial reverso, deve-se estar atento para que não ocorra a eletrossorção dos 
íons liberados do eletrodo de carga contrária, o que muitas vezes é feito usando membranas (Anderson et al., 2010).

Apesar de todas as vantagens apresentadas, a DC vinha sendo pouco estudada até 2009, conforme pode ser observado na Figura 2, porém a partir de 2010, com o estabelecimento de novos grupos de pesquisa na área, o número de publicações vem aumentando progressivamente. Esse cenário pode ser compreendido pelo fato de que, apesar das inúmeras vantagens citadas, o processo ainda era muito dependente do desenvolvimento de materiais capazes de armazenar grandes quantidades de íons, no entanto, com o desenvolvimento de novos eletrodos a pesquisa em DIC deu um grande salto.
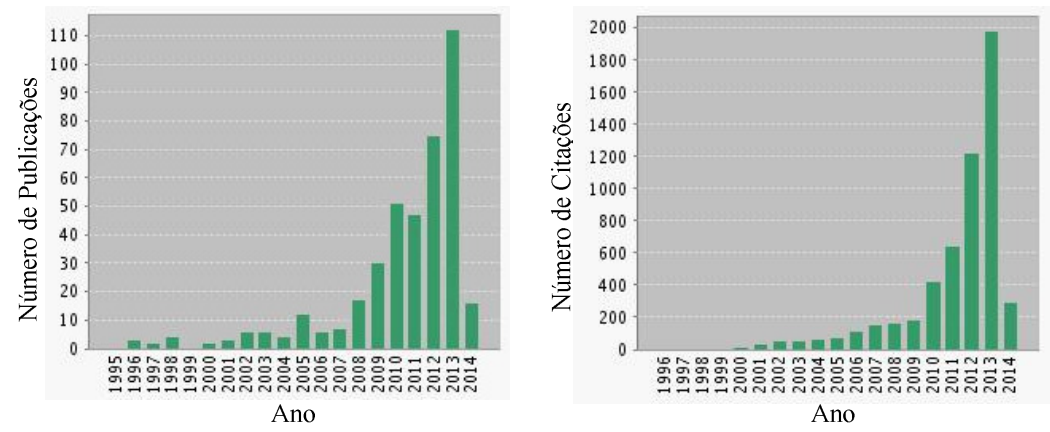

Figura 2 - Número de publicações e número de citações em deionização capacitiva. Fonte: Web of Science (consulta em 27/03/2014).

A escolha do material de eletrodo é um dos principais, senão o principal fator que afeta o rendimento do processo DIC. Um material adequado deve ter as seguintes propriedades: elevada área superficial específica disponível para eletrossorção; 2) condutividade elétrica; 3) rápida resposta de toda a superfície aos ciclos de eletrossorção/eletrodessorção; 4) estabilidade química e eletroquímica em uma ampla faixa de valores de $\mathrm{pH}$ e ser tolerante a freqüentes mudanças de voltagem; 5) fácil conformação de acordo com as necessidades do projeto e 6) baixa propensão a incrustações. Levando em consideração todos esses aspectos, principalmente o primeiro, materiais de carbono têm sido utilizados em processos de eletrossorção (Oren, 2008). Dentre as várias formas de carbono que vêm sendo utilizadas, pode-se destacar o carvão ativo, tecidos de carbono, feltro de carbono, carbon black, nanotubos de carbono e aerogéis de carbono (Frackowiak e Béguin, 2001).

Neste trabalho utilizou-se um tecido de carbono de baixo custo para a dessalinização de uma solução salobra preparada em laboratório. Com o objetivo de aumentar a cinética e a capacidade de eletrossorção, foram estudados diferentes modos de operação de uma célula DIC.

\section{MATERIAIS E MÉTODOS}

Os experimentos de dessalinização foram realizados na célula DIC mostrada esquematicamente na Figura 3(a), onde podem ser identificados os principais componentes que a compõe. A célula é composta por um corpo de acrílico onde são acondicionados dois pares de tecido de carbono fabricados pela Hollingsworth \& Vose (HW), que são separados 
entre si por uma tela de plástico (separador), que além de evitar o curto circuito do sistema permite a passagem da solução salina pela célula.

O tecido de carbono HW é mostrado com detalhes na imagem de microscopia eletrônica de varredura da Figura 3(b), em que se observa sua morfologia fibrosa. Esse material se mostra adequado para uso em eletrossorção devido a sua elevada área superficial específica (BET) de $1466 \mathrm{~m}^{2} / \mathrm{g}$.

A Figura 3(c) mostra uma foto da célula DIC aberta em que é possível observar na placa de acrílico à direita o orifício de saída do eletrólito da célula. Na placa da esquerda é possível observar o separador (tela branca), a borracha de vedação e os eletrodos HW. As dimensões do eletrodo HW eram de $4,3 \mathrm{~cm}$ x $6,2 \mathrm{~cm}$.

O sistema completo é mostrado na Figura (d) e é composto por uma bomba peristáltica, para circulação da solução salina pela célula, de um potenciostato, para controle do potencial ou da corrente, um eletrodo de referência de $\mathrm{Ag} / \mathrm{AgCl}$, um reservatório de eletrólito, um condutivímetro e um multímetro, para medida do potencial ou da corrente. A concentração de sal era determinada através da medida da condutividade da solução.

O sistema operava como mostrado na Figura 3(e), ou seja, em batelada com recirculação. $\mathrm{O}$ eletrólito era bombeado do reservatório (o Erlenmeyer mostrado na figura) para a célula DIC onde ocorria o processo de eletrossorção. Deixando a célula o eletrólito passava pelo condutivímetro, onde a condutividade da solução era registrada on line a cada $10 \mathrm{~s}$ e depois retornava então ao reservatório. Utilizou-se nos experimentos de eletrossorção um volume de $30 \mathrm{~mL}$ de uma solução com $350 \mathrm{mg} / \mathrm{L}$ de $\mathrm{NaCl}$.

(a)
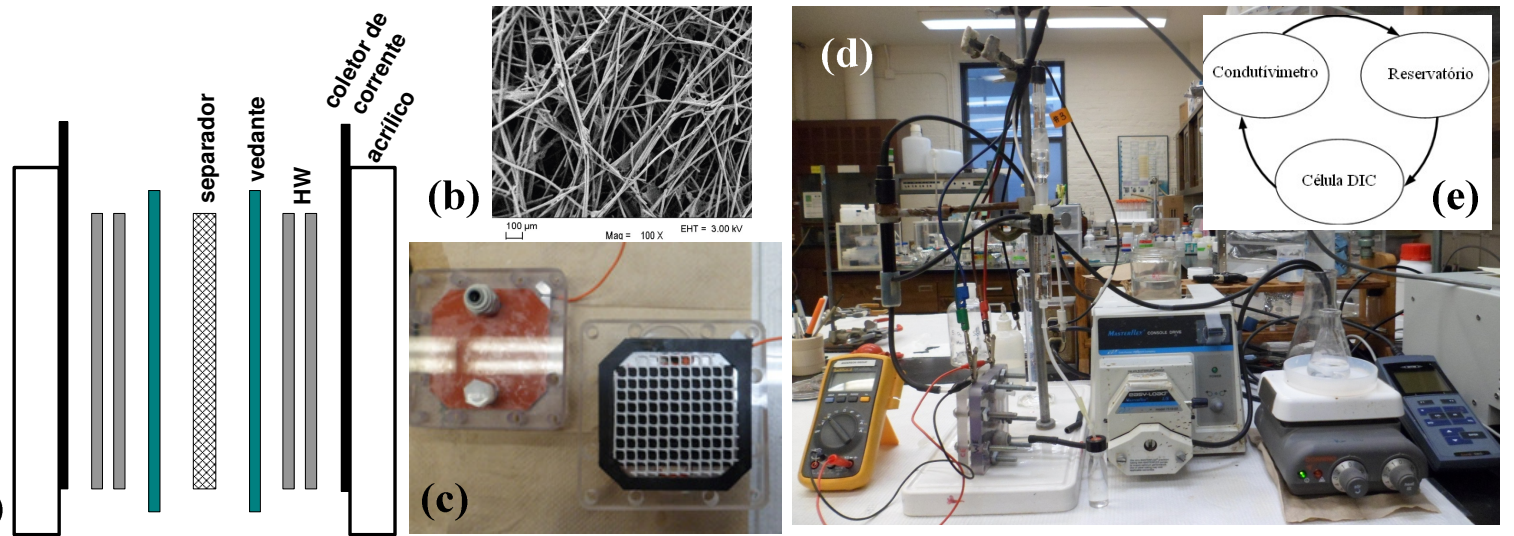

Figura 3 - (a) Representação esquemática da célula DIC; (b) imagem MEV do tecido de carbono HW; (c) foto da célula DIC aberta; (d) sistema experimental e (e) representação esquemático do sistema de eletrossorção em batelada com recirculação.

\section{RESULTADOS E DISCUSSÕES}

Foram realizados experimentos de eletrossorção utilizando potencial pulsante pois se acreditava que seria possível melhorar a difusão e a adsorção no interior dos poros do 
material, conforme ilustrado na Figura 4, para a adsorção de cátions. Foram realizados diversos experimentos variando-se o valor do potencial de pulso negativo e positivo, assim como o tempo em que cada potencial permanecia constante. Os resultados obtidos com potencial pulsante (PP) foram comparados com aqueles obtidos aplicando-se um potencial constante (PC) e os resultados são mostrados na Figura 4(b).

(a)

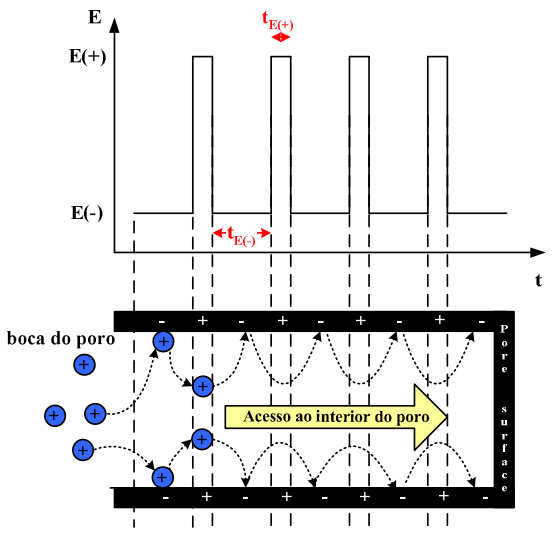

(b)

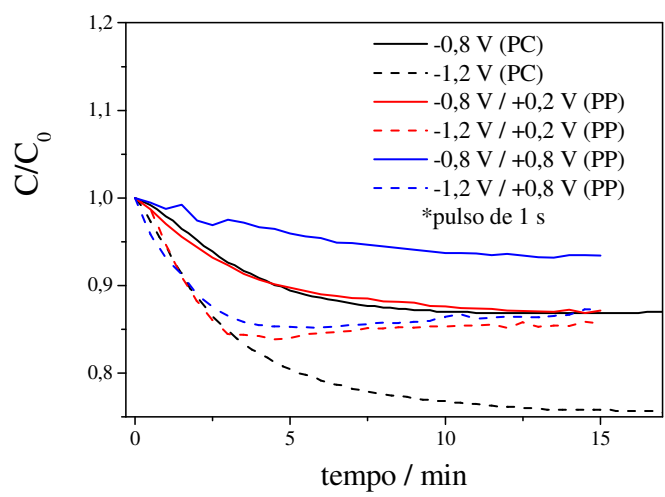

Figura 4 - (a) Representação esquemática da modelo assumido para a eletrossorção no interior do poro durante o processo em potencial pulsante; (b) Concentração normalizada de

$\mathrm{NaCl}$ em função do tempo para os modos de operação a potencial constante e pulsante.

A Figura 4(b) mostra que se pulsando o potencial desde $-0,8 \mathrm{~V}$ para valores menos positivos $(+0,2 \mathrm{~V})$ o resultado em termos de eletrossorção é similar àquele observado aplicando-se um potencial constante de $-0,8 \mathrm{~V}$, porém quando o pulso de potencial é de $+0,8$ $\mathrm{V}$, os resultados em termos de eletrossorção são bastante inferiores. No caso em que o potencial é pulsado de $-1,2 \mathrm{~V}$ para $+0,2 \mathrm{~V}$ ou $+0,8 \mathrm{~V}$, os resultados de eletrossorção são bastante inferiores àqueles obtidos aplicando-se um potencial constante de $-1,2 \mathrm{~V}$. Estes resultados mostram que a hipótese representada na Figura 4 não é válida e que o modo de operação com pulsos de potencial não leva a resultados melhores que aqueles obtidos em condições potenciostáticas.

A Figura 5 mostra uma comparação do processo de remoção de $\mathrm{NaCl}$ aplicando-se corrente e potencial constantes. Os valores de corrente aplicados foram estipulados com base nas correntes iniciais observadas aplicando-se os potenciais de $-0,6 \mathrm{~V}$ e $-0,8 \mathrm{~V}$ (vide Figura 6(b)). Como se pode observar, a aplicação de uma corrente constante leva a uma maior remoção de $\mathrm{NaCl}$ quando a mesma carga é aplicada, ou seja, há uma maior eficiência coulômbica no processo conduzido a corrente constante. Por exemplo, considerando-se o tempo necessário para remover $10 \%$ de $\mathrm{NaCl}$ da solução, foram necessários aproximadamente 9,6 C, 5,7 C e 4,4 C aplicando-se -0,8 V, $20 \mathrm{~mA}$ e $25 \mathrm{~mA}$, respectivamente. Além disso, quando se utiliza o modo galvanostático, há também uma melhoria em termos cinéticos uma vez que a remoção de $10 \%$ de $\mathrm{NaCl}$ ocorreu em $8 \mathrm{~min}, 4,7$ min e 2,9 min aplicando-se $-0,8 \mathrm{~V}$, $20 \mathrm{~mA}$ e $25 \mathrm{~mA}$, respectivamente.

Apesar dos excelentes resultados obtidos utilizando-se o modo galvanostático, o potencial de célula aumenta com o decorrer do processo quando se aplica uma corrente constante. Neste sentido, visando fazer uma comparação mais efetiva entre os dois modos de operação, calculou-se então o consumo energético específico para cada situação. O consumo 
energético específico (CEE) foi calculado considerando-se a energia utilizada para a eletrossorção de uma determinada massa de $\mathrm{NaCl}$. Os resultados de $\mathrm{CEE}$ em função da concentração normalizada de sal na solução é mostrado na Figura 6(a). Como esperado, à medida que a concentração diminui e o eletrodo vai saturando, o CEE aumenta, porém é interessante notar que mais uma vez o modo galvanostático, aplicando-se principalmente uma corrente de $25 \mathrm{~mA}$ apresentou melhores resultados que o modo potenciostático, apresentando valores menores de CEE.

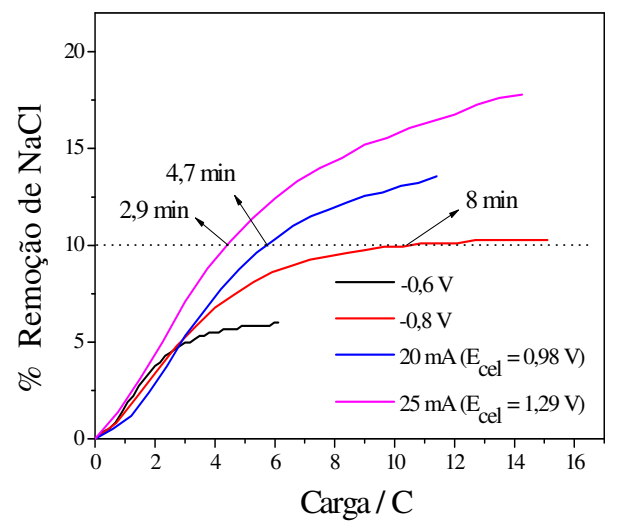

Figura 5 - Porcentagem de remoção em função da carga elétrica aplicada para os modos de operação galvanostático e potenciostático.

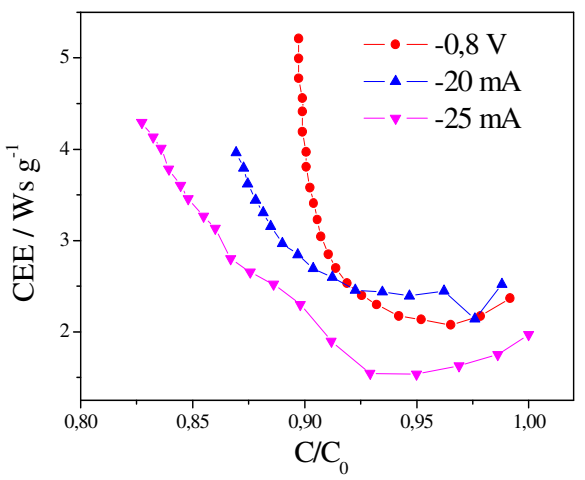

(a)

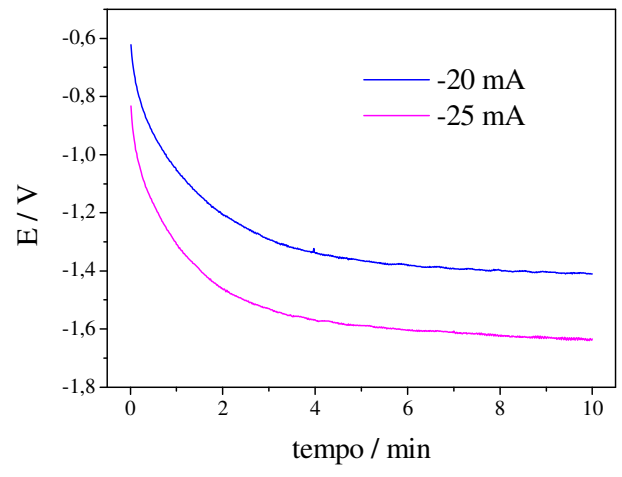

b)

Figura 6 - (a) Consumo energético específico em função da concentração normalizada de $\mathrm{NaCl}$ para os modos de operação potenciostático e galvanostático; (b) Potencial de eletrodo em função do tempo de eletrossorção para o modo galvanostático.

Finalmente, outro aspecto que deve ser observado quando se utiliza o modo galvanostático diz respeito à ocorrência de reações faradáicas que seriam decorrentes de um aumento do potencial de eletrodo a valores superiores aos potenciais das reações de desprendimento de oxigênio (RDO) e hidrogênio (RDH). A Figura 6(b) mostra a evolução do potencial catódico ao longo do processo de eletrossorção conduzido em condições de corrente constante. Como esperado, o potencial torna-se mais negativo à medida que os íons são removidos da solução e atingem valores bastante catódicos em que a RDO está presente. Portanto, para que o modo galvanostático possa ser efetivamente aplicado, deve-se estabelecer um "potencial de corte" em que o processo de eletrossorção deve ser interrompido e então dar-se início ao processo de regeneração. Esse "potencial de corte" corresponde justamente 
àquele em que a RDO e RDH têm início.

No caso da RDO, o potencial de corte seria de aproximadamente de $-1,5 \mathrm{~V}$, ou seja, o processo deveria ser interrompido então após 2,4 min aplicando-se a corrente de $25 \mathrm{~mA}$, ou seja, após a aplicação de 3,6 C. Nesta condição, observando-se a Figura 6, haveria uma remoção de 8,5\% de $\mathrm{NaCl}$ e o CEE médio seria de $1,7 \mathrm{Ws}^{-1}$. Apesar da limitação em termos de remoção quando comparada com as condições de $-0,8 \mathrm{~V}$ ou $20 \mathrm{~mA}$, a aplicação de $25 \mathrm{~mA}$ causa um grande aumento da cinética de remoção, o que levaria a um maior número de ciclos de sorção/dessorção e em termos de CEE, a aplicação de 25 mA ainda seria vantajosa.

\section{CONCLUSÕES}

As principais conclusões do trabalho foram:

$\checkmark$ O uso de pulsos de potencial não levou a nenhuma melhoria no processo de eletrossorção;

$\checkmark$ O modo de operação galvanostático mostrou melhores resultados em termos de remoção de $\mathrm{NaCl}$ e de consumo energético específico quando comparado ao modo potenciostático;

$\checkmark$ Quando se utiliza o modo galvanostático o processo de eletrossorção deve ser interrompido quando se atinge determinado potencial em que as reações faradáicas de desprendimento de oxigênio e hidrogênio ocorreriam.

\section{AGRADECIMENTOS}

Ao CNPq e à FAPESP pelo auxílio financeiro.

\section{REFERÊNCIAS BIBLIOGRÁFICAS}

Anderson M. A., CUDERO A. L., PALMA J. Capacitive deionization as an electrochemical means of saving energy and delivering clean water. Comparison to present desalination practices: Will it compete? Electrochim. Acta, v. 55, p. 3845-3856, 2010.

FRACKOWIAK E., BÉGUIN F. Carbon materials for the electrochemical storage of energy in capacitors. Carbon, v. 39, p. 937-950, 2001.

LEONARD K. C., SUYAMA W., ANDERSON M. A. Improvement of electrochemical capacitor electrodes using $\mathrm{SiO}_{2}$ nanoparticles. Electrochim. Acta, v. 56, p. 10137-10144, 2011.

OREN Y. Capacitive deionization (CDI) for desalination and water treatment - past, present and future (a review). Desalination, v. 228, p. 10-29, 2008.

SOARES T. M., SILVA I. J. O., DUARTE S. N., SILVA E. F. F. Destinação de águas residuárias provenientes do processo de dessalinização por osmose reversa. Rev. Bras. Eng. Agr. Amb., v. 10, p. 730-737, 2006. 